\title{
Opinions of general medical registrars on HIV teaching and their competence in HIV-related clinical issues
}

\author{
T Wingfield, A Herbert and AP Ustianowski
}

\begin{abstract}
More HIV-positive patients are living longer and presenting to non-infection specialties with non-HIV-related issues (eg diabetes, heart disease). National recommendations advise routinely offering HIV testing to all new registrants to primary care and all general medical admissions where community prevalence exceeds 2:1000., ${ }^{1,2}$ It is, therefore, imperative that all physicians are educated and competent in HIV infection, counselling and testing. This study aimed to establish regional medical registrars' opinions on teaching provision, and confidence in, HIV medicine. The results indicated a lack of confidence in HIV medicine and, in those without postgraduate rotations in HIV medicine or infectious diseases, a perception that HIV and infection-related teaching provision is inadequate.
\end{abstract}

KEY WORDS: HIV, infection, postgraduate, education.

\section{Methods}

A cross-sectional, descriptive study evaluating 123 general medical registrars' opinions through a questionnaire distributed at a North West deanery-wide education day was performed. The primary outcome measure was confidence in HIV-related clinical issues (counselling, needlestick advice, opportunistic infections (OIs) and highly active antiretroviral therapy (HAART)) and opinions on HIV and infection teaching (microbiology, tropical medicine, virology, infectious diseases, herein termed 'infection-related' teaching) received as under- and postgraduates. Scoring was from 1-5 ( 1 being poor, 3 adequate, 5 excellent). Secondary outcome measures included frequency of HIV counselling and testing.

\section{Results}

Of 244 registrars within the local deanery, 123 (50\%) attended the education day and $102(83 \%)$ completed the questionnaire. Of these, $17(17 \%)$ had previous postgraduate placements in HIV, genitourinary medicine (GUM) or infectious diseases (ID); the median duration being four months (range 2-23 months).

Fifty-six (55\%) had performed an HIV test on a patient between one and five times over the past six months, but 23

T Wingfield, ${ }^{1}$ specialist registrar; A Herbert, ${ }^{2}$ medical statistician; AP Ustianowski, ${ }^{1}$ consultant

${ }^{1}$ The Monsall Unit, Department of Infectious Diseases and Tropical Medicine ${ }^{2}$ Department of Statistics

North Manchester General Hospital, Manchester
(22\%) had not tested a patient for HIV for over six months (data not shown).

Registrars $(n=102)$ on average felt most competent dealing with needlestick injuries (mean score 3.6/5) and pre-test HIV counselling (3.8/5), adequately competent in OI knowledge (3.0/5) but not competent in post-test counselling $(2.7 / 5)$ or knowledge of HAART (2.3/5) (Fig 1). There were no significant differences in these outcomes with place of qualification or previous HIV/GUM/ID experience (data not shown). Composite undergraduate infection-related teaching (mean average of tropical medicine, HIV, ID, microbiology, and virology teaching combined) was significantly poorer in doctors qualifying from the North West region when compared with those qualifying from other UK regions or abroad ( $\mathrm{p}=0.0001$; Table 1).

Though postgraduate teaching was uniformly scored as inadequate, there was geographical variation. Those qualifying in other UK areas scored their composite postgraduate infectionrelated teaching as better than those from the North West region or those who qualified abroad ( $\mathrm{p}=0.012$; Table 2$)$. Overall, most undergraduate and postgraduate infection-related teaching was rated as less than adequate (Fig 2). Those with previous ID/GUM/HIV exposure $(n=17)$ scored their composite postgraduate infection teaching as significantly better than those without $(n=85)(p=0.0002$; Table 2 and Fig 3$)$.

\section{Discussion}

Since the advent of HAART, there has been a dramatic improvement in the mortality, morbidity and life expectancy of HIV-positive patients. ${ }^{3}$ Consequently, more are presenting to non-infection healthcare professionals with issues not directly related to HIV (eg diabetes, heart disease) and agerelated diseases. ${ }^{4}$ Recent guidelines suggest that general medical admissions and general practitioner registrants should routinely be offered HIV testing in an area where community prevalence exceeds 2:1000. ${ }^{1,2}$ Therefore, general physicians should become competent in HIV counselling and testing, and in their knowledge of HIV-specific clinical issues. There are no significant data in the literature investigating clinicians' perceptions of their training and competence in these issues.

This study demonstrated a distinct, perceived lack of knowledge of HAART. Poor HAART prescribing practices by noninfection specialty doctors for HIV inpatients has been previously recognised, ${ }^{5}$ with estimated errors in up to $25 \%$ of inpatient 


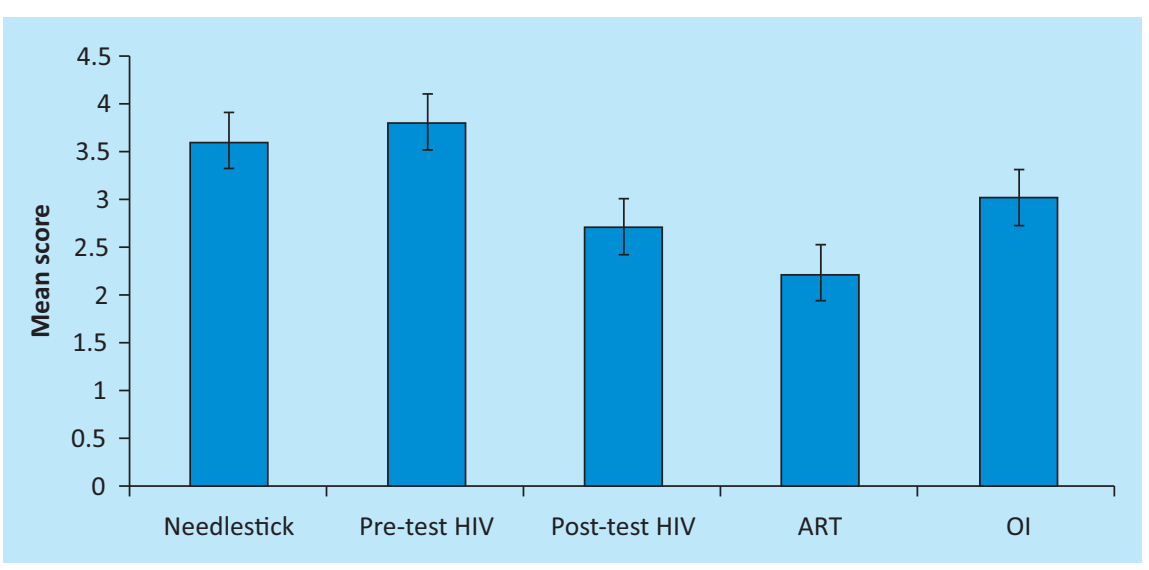

Fig 1. Responders mean competency scores in dealing with needlestick injuries, pre-test HIV counselling, post-test HIV counselling, anti-retroviral therapy and opportunistic infections. 1 = not at all competent; 3 = sufficiently competent; $5=$ very competent. Bars represent confidence intervals.

errors. ${ }^{9}$ Lack of confidence surrounding HIV medicine appeared to be independent of previous experience in GUM/HIV/ID, year or place of qualification. This may indicate that despite this previous specialty experience and - as shown in Fig 3 - better postgraduate teaching, clinicians feel they de-skill quickly when not exposed to HIV medicine on a regular basis. HIV teaching sessions would therefore be best provided regularly.

These results indicate that registrars in the Manchester region are performing relatively few HIV tests despite British HIV Association/National Institute for Health and Clinical Excellence (BHIVA/NICE) guidelines in an area with a local HIV prevalence of $3.5-5 / 1000 .^{10}$ This may be related to lack

Table 1. Composite undergraduate teaching scores in relation to place of education.

\begin{tabular}{|c|c|}
\hline $\begin{array}{l}\text { Mean (SD) undergraduate } \\
\text { composite teaching score }\end{array}$ & $\begin{array}{l}99 \% \text { confidence } \\
\text { interval for the } \\
\text { mean }\end{array}$ \\
\hline
\end{tabular}

$\begin{array}{lll}\begin{array}{l}\text { Local region } \\ (\mathrm{n}=28)\end{array} & 2.47(0.54) & 2.19 \text { to } 2.75 \\ \begin{array}{l}\text { Other region, UK } \\ (\mathrm{n}=40)\end{array} & 3.08(0.71)^{*} & 2.77 \text { to } 3.38 \\ \begin{array}{l}\text { Non-UK } \\ (n=23)\end{array} & 3.19(0.64)^{*} & 2.83 \text { to } 3.56\end{array}$

*P $=0.0001$ (ANOVA) difference between local region vs either other UK region or non-UK.

HAART prescriptions. ${ }^{6,7}$ This may lead to:

- additional toxicity

- decreased compliance

- harmful drug-drug interactions

- creation of drug resistance. ${ }^{5,8}$

Trained HIV pharmacist participation and better education in multidisciplinary teams has been shown to mitigate these of confidence or training. It is essential that testing be offered early to avoid late presentation (at low CD4 counts), poor response to HAART and subsequent increased mortality. ${ }^{11-13}$

Overall, general medical registrars perceive both under- and postgraduate teaching in infection-related subjects to be poor. Only microbiology and ID teaching were scored as adequate at an undergraduate level; all other teaching was scored as inadequate. With a large proportion of admissions and general practitioner consultations being infection-related (including methicillin-resistant Staphylococcus aureus, Clostridium difficile), it is essential these subjects are taught well. Of note, the 2009 UK curricula for general internal medicine makes scarce reference to infection-related areas with HIV being mentioned only four times in 191 pages. ${ }^{14}$

There are several drawbacks to this study. Firstly, despite an $83 \%$ response rate, numbers are small and cannot be applied nationally. Secondly, the sample only represented half the general medical registrars in the deanery. Thirdly, how respondents rated quality of other specialty teaching received was not assessed, so comparisons with infection-related teaching cannot be made.

\section{Conclusions}

Medical registrars do not feel competent in their knowledge of HAART or post-test counselling and feel both undergraduate

Table 2. Comparison of mean composite scores for postgraduate teaching related to previous infectious disease (ID) experience.

\begin{tabular}{|c|c|c|c|c|c|c|}
\hline & $\begin{array}{l}\text { Mean (SD) postgraduate } \\
\text { composite teaching score }\end{array}$ & $\begin{array}{l}99 \% \text { confidence } \\
\text { interval for the mean }\end{array}$ & Comparison & Difference & $\begin{array}{l}99 \% \text { confidence interval } \\
\text { for difference in means }\end{array}$ & $\begin{array}{l}\text { p-value } \\
\text { (two-sided) }\end{array}$ \\
\hline $\begin{array}{l}\text { No previous ID } \\
\text { experience }\end{array}$ & $2.36(0.64)$ & 2.18 to 2.55 & $\begin{array}{l}\text { No previous ID } \\
\text { experience }\end{array}$ & & & \\
\hline $\begin{array}{l}\text { Previous ID } \\
\text { experience }\end{array}$ & $3.1(0.93)$ & 2.42 to 3.78 & $\begin{array}{c}v \\
\text { previous ID } \\
\text { experience }\end{array}$ & -0.74 & -1.23 to -0.24 & 0.0002 \\
\hline
\end{tabular}




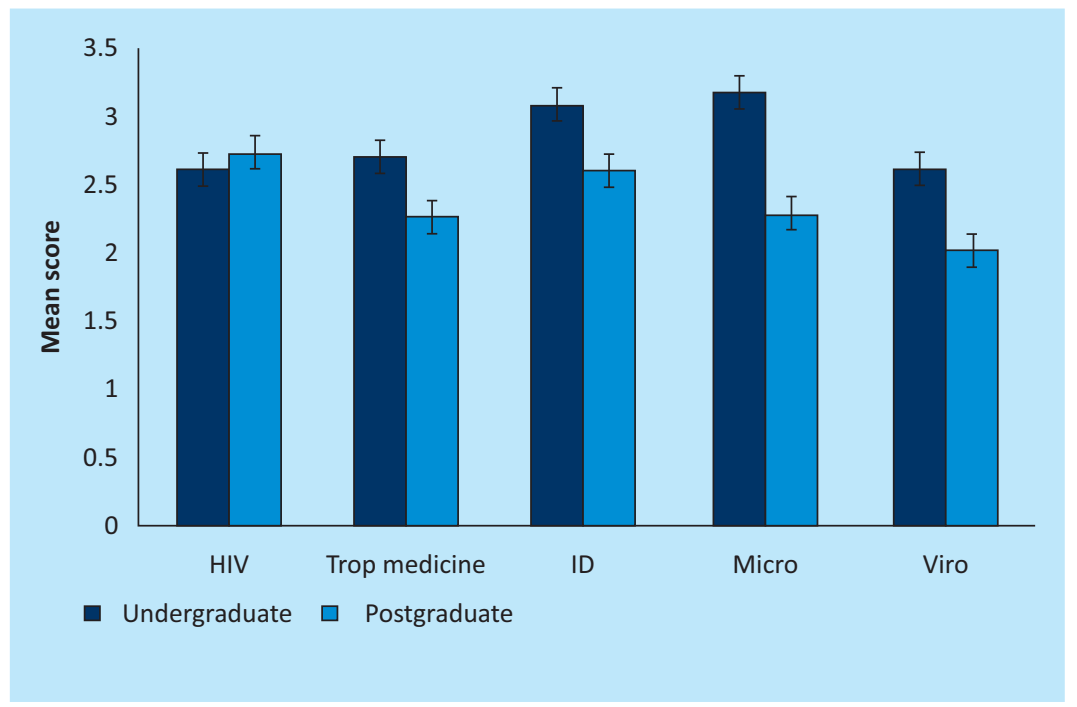

Fig 2. Breakdown in perception of respondents of their undergraduate and postgraduate teaching by specific subject - HIV, tropical medicine, infectious diseases, microbiology and virology. $1=$ did not receive teaching; 2 = inadequate teaching; 3 = adequate teaching; $4=$ good teaching; $5=$ excellent teaching. Bars represent confidence intervals.

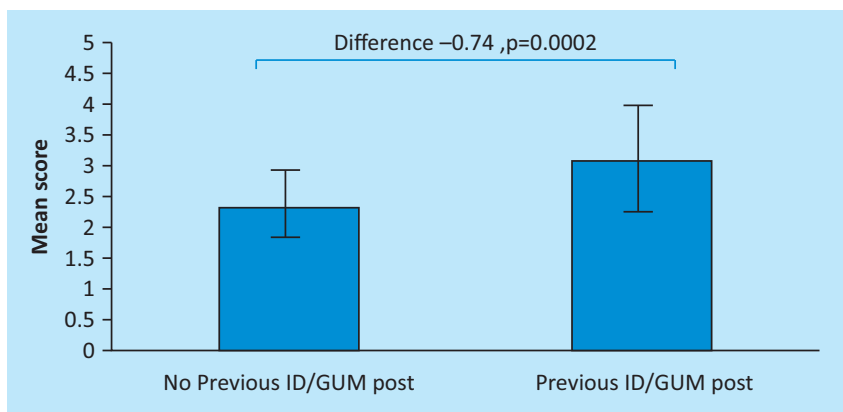

Fig 3. Mean postgraduate composite teaching score related to previous infectious diseases (ID), genitourinary medicine (GUM) and HIV experience. 1 = did not receive teaching; 2 = inadequate teaching; 3 = adequate teaching; 4 = good teaching; 5 = excellent teaching. Bars represent confidence intervals.

and postgraduate HIV and infection teaching has been inadequate. Teaching in these areas significantly improved with preregistrar exposure to ID/GUM/HIV.

\section{References}

1 British HIV Association. UK national guidelines for HIV testing. London: BHIVA, 2008. www.bhiva.org/documents/ Guidelines/Testing/GlinesHIVTest08.pdf

2 National Institute for Health and Clinical Excellence. Increasing the uptake of HIV testing of black Africans in England. London: NICE, 2011. www.nice.org.uk/nicemedia/live/13417/53591/53591.pdf

3 Mocroft A, Ledergerber B, Katlama C et al. Decline in the AIDS and death rates in the EuroSIDA study: an observational study. Lancet 2003;362:22-9.

4 Palella FJ, Baker RJ, Moorman AC et al. Mortality in the highly active antiretroviral therapy era. J Acquir Immune Defic Syndr 2006;43:27-34.
5 Arshad S, Rothberg M, Rastegar DA et al. Survey of physician knowledge regarding antiretroviral medications in hospitalized HIV-infected patients. J Int AIDS Soc 2009;12:1-10.

6 Purdy BD, Raymond AM, Lesar TS et al. Antiretroviral prescribing errors in hospitalized patients. Ann Pharmacother 2000;34:833-8.

7 Rastegar DA, Knight AM, Monolakis JS et al. Antiretroviral medication errors among hospitalized patients with HIV infection. Clin Infect Dis 2006;43:933-8.

8 Harrigan PR, Hogg RS, Dong WW et al. Predictors of HIV drug-resistance mutations in a large antiretroviral-naive cohort initiating triple antiretroviral therapy. J Infect Dis 2005;191:339-47.

9 Heelon M, Skiest D, Tereso G et al. Effect of a clinical pharmacist's interventions on duration of anti-retroviral-related errors in hospitalized patients. Am J Healthcare Syst Pharm 2007;64:2064-8.

10 Health Protection Agency. Areas where wider HIV testing policies should be considered. www.hpa.org.uk/web/HPAwebFile/HPAweb_ C/1221722386448

11 Robbins GK, Spritzler JG, Chan ES et al. Incomplete reconstitution of $\mathrm{T}$ cell subsets on combination antiretroviral therapy in the AIDS Clinical Trials Group protocol 384. Clin Infect Dis 2009;48:350-61.

12 Marin B, Thiébaut R, Bucher HC et al. Non-AIDS-defining deaths and immunodeficiency in the era of combination antiretroviral therapy. AIDS 2009;23:1743-53.

13 Sabin CA, Smith CJ, Gumley H et al. Late presenters in the era of highly active antiretroviral therapy: uptake of and responses to antiretroviral therapy. AIDS 2004;18:2145-51.

14 Joint Royal College Postgraduate Training Board. Specialty training curriculum for general internal medicine. London: JRCPTB, 2009. www.jrcptb.org.uk/specialties/ST3-SpR/Documents/ 2009\%20GIM\%20curriculum.PDF

Address for correspondence: Dr T Wingfield,

4 Curtis Street, Levenshulme, Manchester M19 3ND.

Email: tomwingfield@hotmail.co.uk 